\title{
Portugal Livre: um jornal de oposição ao Estado Novo português no Exílio brasileiro 1958-1961*
}

\author{
Portugal Livre: an opposition newspaper to the Portuguese Estado Novo in the Brazilian \\ Exile 1958-1961
}

\author{
Franco Santos Alves da Silva \\ Doutorando em História pela \\ Universidade Federal de Santa Catarina \\ alvesfranco@hotmail.com
}

Resumo: Este artigo versa sobre as ideias e discussões acerca da fundação, manutenção e fechamento do jornal Portugal Livre, editado na cidade de São Paulo, Brasil, por portugueses exilados do Estado Novo naquele país, na viragem dos anos cinquenta para sessenta. A proposta é estudar não somente o jornal em si, mas sim os debates que antecederam sua criação e permeavam assuntos de como a oposição deveria agir no exílio; os posicionamentos frente à questão colonial; e os diferentes partidos políticos envolvidos. Assim, o corte temporal é um pouco maior do que a vida do jornal em si, compreendendo o período entre os anos 1958 e 1961.

Palavras-chave: Exílio, Portugal, jornal.

\begin{abstract}
This article deals with the ideas and discussions about the foundation, maintenance and closing of Portugal Free newspaper, published in São Paulo, Brazil, for Portuguese exiles the New State in the country at the turn of the fifties to sixties. The proposal is to study not only the newspaper itself, but the discussions leading up to its creation and permeated issues of how the opposition should act in exile; the positions opposite the colonial question; and the different parties involved. Thus, the temporal cut is slightly larger than the paper's life itself, comprising the period between 1958 and 1961 .
\end{abstract}

Keywords: Exile, Portugal, newspapers.

\footnotetext{
* Este artigo é fruto da pesquisa para o mestrado em história contemporânea realizado na Universidade do Porto, Portugal.
} 


\section{Introdução}

O Portugal Livre teve vida efêmera, fundado em São Paulo, foram apenas dezesseis edições, entre novembro de 1959 e março de 1961. Pode ser considerado pequeno se comparado ao jornal Portugal Democrático, igualmente publicado no Brasil, com duração de dezessete anos e mais de duzentas edições, no entanto isto não diminui sua importância para a História, sobretudo porque ele foi fundado em meio às divergências políticas entre o grupo de portugueses exilados em território brasileiro. $\mathrm{O}$ jornal contou com a colaboração de Humberto Delgado, Henrique Galvão, Victor da Cunha Rego, Miguel Urbano Rodrigues, João Santana Mota, João Alves das Neves, Joaquim Ribeiro Bastos Paulo de Castro, Pedroso Lima e o brasileiro Claudio Abramo como diretor, mesmo cargo que exercia a frente do jornal O Estado de S. Paulo. É certo que a duração do jornal não pode ser um parâmetro para medir seu impacto dentro do contexto da oposição portuguesa ao Estado Novo no exílio brasileiro, bem da verdade concluímos o oposto: o que um jornal, editado no exílio e de vida tão curta, pode revelarnos acerca da oposição ao Estado Novo? É com esta pergunta chave que buscamos desenvolver o texto. Contudo, veremos antes algumas questões gerais sobre o Estado Novo e os exilados políticos, em especial, em terras brasileiras.

\section{O Estado Novo e a questão do exílio}

A ditadura portuguesa, ou Estado Novo e Antonio Oliveira Salazar, entre 1928 e 1974, gerou umas das maiores ondas de emigração política da Europa, equiparando-se somente com a Guerra Civil na Espanha (SILVA, 2006:179). Os destinos escolhidos por estes emigrantes eram vastos, tais como Europa, América do Norte e Latina e Norte da África, especialmente Argélia. Na Europa, a Espanha, antes do franquismo, recebeu alguns exilados, assim como Bélgica e Luxemburgo, mas mais tardiamente, contudo França foi o país europeu com maior número de exilados portugueses. Já no continente americano encontram-se diversos grupos, como nos Estados Unidos da América, Argentina, México, Venezuela, e o Brasil, do qual trataremos (SILVA, 2006: 181). O maior fluxo de imigrantes políticos portugueses para o Brasil foi a partir década de 50, em parte devido ao fato de Portugal ter entrado para a Organização do Tratado do Atlântico Norte (OTAN), que permitiu um maior fôlego e estruturação interna por parte 
do regime e consequentemente apertou ainda mais a repressão política, e fez com que muitas pessoas deixassem o país.

Entre 1958 e 1974 cerca de 1,5 milhões de portugueses deixaram sua terra natal para se radicarem em outros locais. O Brasil, até a década de 1950 era um dos principais destinos para os portugueses, e foi o maior, dentre todos os destinos, nos anos que corresponde este trabalho, entre 1958 e 1960. Apesar disso acabou perdendo espaço para países aonde não era necessária a longa travessia oceânica, que poderia ser mais cara e burocrática, e acabaram por se radicar na Europa central (FREITAS, 1990: 91).

Um dos fatores de extrema relevância ao tratar dos exilados do Estado Novo está ligado à longevidade do regime. Parece lugar comum fazer esta afirmação sempre que se aborda tal temática, mas na verdade é sempre necessário fazê-lo, para evitar assim problemas de conceitos e contextualizações. Se, para analisar a natureza ideológica do regime de Oliveira Salazar não pode se perder de vista a sua dimensão no tempo, o mesmo se refere quando tratamos de seus opositores, e por consequência, exilados.

O exílio é um evento - ou fenômeno - que sempre esteve presente na História, contudo, na contemporaneidade ele apresentou proporções maiores, segundo Fabio Oliveira "o século XX produziu um tipo muito característico de intelectual, envolvido intimamente com as principais tramas de seu tempo e marcado pela tendência multifacetada e totalizante, com atividade política engajada que lhes rendeu uma vida de exílios e fugas" (OLIVEIRA, 2010: 250). Enquanto que Heloisa Paulo ressalta que as ligações pelas quais estão unidos os homens do século passado, perpassam por momentos como revoluções, duas grandes guerras, guerra civil, mudanças de regimes e golpes de estado, fatos que fortaleceram o estabelecimento de "laços" (PAULO, 2010b: 96).

O Centro Republicano Português, cuja sede era em São Paulo, existia no Brasil desde 1908 e congregava boa parte da oposição no exílio brasileiro, tornando-se assim uma sede social e ponto de referência para os exilados que aos poucos chegavam. Deste grupo, sairiam os responsáveis pela edição do jornal Portugal Democrático e os que davam vida ao Comitê de Intelectuais Portugueses na década de 1950.

Sarmento Pimentel foi figura chave na organização e inserção de uma nova geração de exilados no Brasil. Em virtude da amizade de Pimentel o com diretor do jornal O Estado de S. Paulo, Ruy Mesquita Filho, diversos jornalistas portugueses encontraram trabalho na redação do jornal, sobretudo o grupo demitido, em razão de censura, do jornal lisboeta Diário Ilustrado, entre estes jornalistas estavam Miguel Urbano Rodrigues, que participou de jornais oposicionistas no Brasil como Portugal Democrático e Portugal 
Livre $^{1}$. Este contato pré-estabelecido entre as redações dos jornais é um exemplo claro de um caminho que a vida de exilado poderia tomar, pois se baseava em uma rede de conexões e ajuda mutua que, neste caso, acabaram por influenciar os rumos que a luta desta nova geração de oposicionistas realizou no Brasil (BATISTA, 2007: 57).

As redes de contato eram fator chave e que pesavam na escolha do destino. Neste caso as possibilidades e abertura com que Urbano Rodrigues teve com os jornalistas brasileiros permitiram que novos exilados viessem para o Brasil, sob sua indicação. Como por exemplo, dois outros jornalistas provenientes do Diário Ilustrado, que vieram fazer parte do quadro do jornal $O$ Estado de S. Paulo, Victor da Cunha Rego e João Alves das Neves, ambos residiram temporariamente na casa de Urbano Rodrigues, com suas respectivas esposas ${ }^{2}$ (SILVA, 2006: 152).

Este novo contingente recém-chegado ao Brasil contrastou com a colônia de portugueses já existentes lá, porém, excluindo a nacionalidade em comum, os motivos que os reuniam no mesmo país eram distintos, e, portanto, eram igualmente distintas as categorias ou classificações destes novos portugueses. Desta forma, eram "imigrantes políticos" e não "imigrantes econômicos". Bem da verdade, a categoria imigrante pode não ser suficiente, ou mesmo válida, o mais preciso seria exilado ou refugiado. Nesta mesma linha de pensamento também não podemos nomeá-los como colônia e sim diáspora (SILVA, 2006:54).

A década de 1950 no Brasil foi palco de encontro de duas gerações de exilados, distintas na idade e experiência histórica e, sobretudo, formação ideológica. O grupo com o qual Heloisa Paulo vem pesquisando trata-se de uma primeira geração, que viu, e muitas vezes participou, da instauração da República portuguesa e fez oposição à Ditadura na década de 1930, antes mesmo da instauração do Estado Novo. Esta geração tem formação mais conservadora, composta ainda por monárquicos e republicanos, que tem em Jaime

\footnotetext{
${ }^{1}$ Miguel Urbano Rodrigues é jornalista, escritor e político. Retornou para Portugal após a Revolução dos Cravos (1974). Foi chefe de redação, entre 1974 e 75, do jornal comunista Avante!, Nesta mesma linha política foi diretor do jornal Diário, entre 1976 e 1985. Entre 1990 e 95 foi deputado da Assembleia portuguesa pelo Partido Comunista Português. Assim como membro do Conselho da Europa. Entre os quase vinte livros publicados há reportagens, ensaios, contos, romances, memórias e crônicas políticas.

${ }^{2}$ Victor da Cunha Rego era o jornalista português com mais abertura com os jornais brasileiros. Escreveu para $O$ Estadão e A Folha de SP. Casou e teve dois filhos, o que fez com que se exilasse novamente após o Golpe Militar de 1964, foi para Argélia, Iugoslávia e Itália. Voltou para Portugal após a Revolução dos Cravos (1974). Fundou a Editora Perspectiva \& Realidades, que publicava principalmente livros políticos de apoio ao socialismo. Participou da fundação do Partido Socialista em Portugal em 1974, foi diretor do Diário de Notícias, e presidente da Radio Televisão Portuguesa RTP em 1980. Cronista político diário, teve vários livros publicados, entre romances, ensaios e crônicas. Faleceu de câncer aos 66 anos, em janeiro de 2000 .
} 
Cortesão e Sarmento Pimentel dois exemplos. Já a segunda geração, da qual tratam autores como Fábio Ruela e Douglas Mansur, são de exilados que nasceram, ou cresceram, dentro do regime, e participaram das instituições paramilitares de caráter fascista como a Mocidade Portuguesa e Legião Portuguesa, na segunda metade da década de 30. Houve então, um de mentalidades e divergências políticas, cuja compreensão destas diferenças ideológicas pode resultar em uma interpretação mais rica e dinâmica sobre o funcionamento e debates que a oposição travou a partir do exílio.

\section{Portugal Democrático: o jornal pioneiro}

Estabelecido na cidade de São Paulo, o professor Vítor Ramos juntamente com Manuel Ferreira de Moura, fundam o jornal Portugal Democrático na tentativa de agrupar este contingente de exilados. O jornal durou mais de duzentas edições mensais, entre 1956 e 1974, e possuía como objetivo denunciar as irregularidades e ilegalidades do Estado Novo para o mundo, além de manter a colônia portuguesa - e a sociedade brasileira de uma forma geral - atualizada com os fatos e o clima tenso em Portugal e posteriormente o andamento da Guerra Colonial na África. Em seu quadro de redatores e colaboradores passaram nomes como Barradas de Carvalho, Victor da Cunha Rêgo, Miguel Urbano Rodrigues, Sarmento Pimentel, Jaime Cortesão, Jaime de Morais, Jorge de Sena, Maria Archer, Vitor Ramos, Adolfo Casais Monteiro, Fernando Lemos, Fernando Muralha, Joaquim Quitério entre outros que se dividiam entre uma série de funções como diagramação, editoração, anúncios, impressão, distribuição, assinaturas, doações de terceiros e muitas outras. O grupo contou, ao longo de seus quase 19 anos, com o apoio de diversos intelectuais brasileiros como os sociólogos Florestan Fernandes e Octávio Ianni e dos historiadores Sérgio Buarque de Holanda, Caio Prado Júnior e Carlos Guilherme Mota (RAMOS, 2004).

A proposta foi muito além do que editar um jornal, e sim, servir como um ponto de referência para todos os exilados em terras brasileiras. Organizou encontros e congressos, como o Comité Pró-Anistia de Presos Políticos, bem como discussões em universidades brasileiras sobre temas portugueses, mas que interessavam ao mundo inteiro, tal como o colonialismo. Caracterizava-se como um movimento que articulou os integrantes com a sociedade brasileira com uma rede de contados com opositores exilados em outros países, contribuindo para uma rede internacional de emigrados (SILVA, 2006: 
25). Porém mesmo escrito a partir do exílio, era pautado por questões que aconteciam dentro de Portugal, exemplo disto é a orientação da luta do Partido Comunista Português na segunda metade da década de 1950, quando se optou por uma luta pacífica.

Inicialmente era caracterizado pela formação heterogênea de sua redação e colaboradores, como os republicanos liberais João Sarmento Pimentel e seu irmão Francisco Pimentel, e uma célula do Partido Comunista Brasileiro, da qual portugueses faziam parte alguns portugueses e monarquistas como Thomaz Ribeiro Colaço, além de anarquistas e socialistas. A unidade sempre foi um tema corrente entre os artigos e crônicas nas páginas do Portugal Democrático, contudo foi aos poucos sendo liderado quase que exclusivamente pelo núcleo comunista, o que acabou por desagradar outros envolvidos. Assim a solução pacífica adotada pela redação batia de frente com as novas questões e efervescências recém trazidas de Portugal por Humberto Delgado e foi questão de meses para que estas divergências se tornarem incontornáveis.

O jornal se viu obrigado a adaptar-se à conjuntura política brasileira, a qual vivia uma ascensão das esquerdas e havia passado por um golpe militar em 1964, forçando o grupo a silenciar frente a esta questão, caso quisessem sobreviver a esta nova situação de duplo exílio. Muitos deixaram o Brasil, outros mudaram o tom de seu ataque a Salazar, centralizando a crítica em cima da guerra colonial em curso. Haja vista a condenação internacional ao colonialismo, que contava com o apoio da ditadura militar brasileira. Ainda assim foi o único jornal editado no país que conseguia falar abertamente em marxismo e luta de classes sem ser impedido pela censura. Entre os últimos anos tratou de denunciar os abusos e violações dos diretos humanos junto à Organização das Nações Unidas (ONU) e a fazer críticas a falta abertura de Marcello Caetano. Mas voltaria a utilizar e apoiar a abordagem direta na oposição ao Estado Novo.

A vinda do general Humberto Delgado para o Brasil foi um divisor de águas ${ }^{3}$. Ele era um homem do regime, anticomunista, apoiou tanto no golpe militar, quanto na instauração do Estado Novo. Foi condecorado e representava Portugal em diversas

\footnotetext{
3 Humberto da Silva Delgado, o "militar sem medo", foi general da aeronáutica portuguesa. Participou do Golpe de 1926 que levaria ao Estado Novo. Entre as diversas funções, foi adido militar na embaixada norteamericana de Washington por cinco anos, onde mudou sua visão acerca de Salazar. Foi convidado pela Oposição a ser candidato à Presidência da República. Cujas eleições eram organizadas de maneira simbólica, pois além de candidatos e resultados arranjados, era o Presidente do Conselho de Ministros quem tinha o real poder. A campanha tomou enormes proporções, levando uma massa de portugueses às ruas. Com o resultado fraudado, vítima de represálias e pressionado pela polícia política, exilou-se no Brasil. Na volta a Portugal orquestrou, em 1962, o fracassado Golpe da Beja. Foi assassinado por agentes da PIDE em uma emboscada no ano 1965, junto com sua secretária brasileira Arajaryr Campos, em Badajoz, perto da fronteira com a Espanha.
} 
questões internacionais. Quando morou por cinco anos nos Estados Unidos da América, como adido militar da Embaixada Portuguesa e membro militar da OTAN, tomou conhecimento da democracia americana, e sua visão acerca do salazarismo começou a mudar, até ser convidado pela oposição para ser candidato à Presidência da República (DELGADO, PACHECO \& FARIA, 1998). Possuía formação ideológica forjada dentro dos quadros militares do Estado Novo, com todos de sua geração. Seu rompimento com o regime, e sua "tomada de consciência" sobre o funcionamento da democracia, sobretudo a americana, não resultaram em uma visão progressista do mundo. Assim seu comportamento e relação com os demais, era sempre pautada por uma concepção autoritária do trabalho político (RODRIGUES, 2002b: 158).

O jornal Portugal Democrático, juntamente com a imprensa brasileira, foram um dos grandes responsáveis em divulgar cada passo do longo calvário de Delgado até o exílio, e, desta forma, ajudou a consolidar sua imagem de líder sufragado. Entre os editoriais houve a publicação de suas cartas enviadas para ministros e membros das forças armadas. Uma destas, endereçada ao ministro do interior, o general pedia para diminuir a brutalidade utilizada pela Polícia Internacional de Defesa do Estado (PIDE), principalmente na prisão de Caxias, e apelava para a condenação internacional para os abusos cometidos pela polícia política.

A concessão de asilo político por parte do governo brasileiro para Delgado, depois das eleições de 1958, causaram furor e animo à comunidade de portugueses exilados, e acabou por criar uma onda de esperança e expectativa naquele grupo. Contudo, logo este ânimo se dissiparia com as opiniões políticas e tomadas de decisões de Delgado sobre como deveria se reorganizar a oposição ao Estado Novo a partir do Brasil. O general trouxe consigo a sigla do Movimento Nacional Independente (MNI) e lançou uma diretiva que nomeava pessoas conforme sua vontade, fez ainda críticas diretas ao núcleo de oposicionistas situados em São Paulo, sobretudo organizados no jornal Portugal Democrático, afirmou que este era um núcleo de comunistas, e que contrariava a opção de ver Portugal, livre de fato. Em meio a este contexto alguns exilados, descontentes com a linha editorial do Portugal Democrático, procuraram Delgado e fundaram o jornal Portugal Livre. 


\section{Portugal Livre: Uma nova opção de luta a partir do Brasil}

Não é por coincidência que a vida do Portugal Livre situa-se em anos muito conturbados para o Estado Novo, cujo início se dá com a campanha eleitoral de 1958 e o candidato Humberto Delgado, o "general sem medo", seguido de diversos outros eventos tais como a Revolta da Sé em março de 1959 e a fuga do capitão Henrique Galvão no mesmo ano ${ }^{4}$. Em janeiro de 1960, Álvaro Cunhal, Joaquim Gomes, Carlos Costa, Francisco Miguel, Jaime Serra, José Carlos, Guilherme Carvalho, Pedro Soares, Rogério de Carvalho e Francisco Martins Rodrigues evadiram da prisão depois de uma ação detalhadamente preparada e sincronizada. Iniciando o "ano maldito de Salazar", tem-se o sequestro do paquete Santa Maria pelo Directório Revolucionário Ibérico de Libertação (DRIL) em janeiro de 1961, seguido do início da guerra colonial em Angola no mês seguinte ${ }^{5}$. Já entre março e abril desenrola-se a tentativa de restauração interna, conhecida como Golpe Botelho Moniz, enquanto que ao fim do ano, em novembro, um avião da TAP, linha Casablanca-Lisboa, arremessou panfletos sobre a capital portuguesa. Em dezembro ocorreu a revolta em Goa, a fuga de mais oito dirigentes e militantes comunistas da prisão de Caxias, e, finalmente, a revolta da Beja, na viragem do último dia do ano de 1961. Muitas destas ações estiveram fortemente presentes na redação do jornal e na vida de seus participantes, em alguns casos, de forma direta.

Haviam outros oposicionistas, jornalistas e compatriotas espalhados pelo mundo, como na Venezuela, Espanha, Inglaterra, França, Angola, entre outros. Toda a ação, fundação e os debates que envolveram o jornal Portugal Livre desenrolaram-se fora do território português, tendo o Brasil como sede. Não obstante, é necessário ressaltar o grande destino migratório que esta nação se tornou na segunda metade do século XX: somente "na década de 1951-1960 emigraram para o Brasil 235635 dos 358705

\footnotetext{
${ }^{4}$ Henrique Galvão, foi capitão do Exército português, inspetor de Administração das Colónias, grande propagandista do colonialism0 português. Foi governador de Huila, Angola. Foi descoberto, junto com outros militares, em uma tentativa de golpe contra o Estado Novo, foi preso e expulso do exército. Em uma manobra conseguiu asilo na embaixada da Argentina em Lisboa e depois exilou-se na Venezuela. Reunião em torno de si oposicionistas anticomunistas. No país latino fundou o DRIL e teve uma passagem turbulenta pelo Brasil depois do assalto ao Santa Maria. Escreveu mais de 50 livros, entre crônicas de viagem, relatos sobre a África, romances, o tema principal era o Império Português e escritos políticos.

5 DRIL era um movimento fundado por Henrique Galvão e outros líderes espanhóis que buscavam lutar contra Francisco Franco e Salazar. A maior ação foi a tomada do transatlântico português Santa Maria em 22 de janeiro em mares caribenhos, que zarpou de Miami dia 9 de janeiro de 1961. A bordo estavam 612 passageiros, 350 tripulantes, e 21 integrantes do DRIL, entre eles Henrique Galvão. Um tripulante ofereceu resistência e foi morto, A marinha Americana acompanhou o navio até a costa brasileira, quando parou no Recife em 2 de fevereiro, quando Miguel Urbano Rodrigues subiu a bordo. Inicialmente queriam navegar até Angola, fazer a independência e a partir de lá derrubar o Estado Novo.
} 
portugueses que abandonaram o país no mesmo período, o que representa mais de $65 \%$ do total" (ALMEIRA BARRETO:1970: 225).

A redação do jornal situava-se na cidade de São Paulo, que a exemplo do Brasil, passava por um crescimento vertiginoso, solidificando-se como grande polo industrial após estabelecimento de indústria automobilista em sua região metropolitana. Nesta cidade também situava-se alguns dos maiores jornais do país, como o OESP e Folha da Manhã (hoje Folha de S. Paulo). O próprio país passava por grandes transformações socioeconômicas marcadas pela chegada da televisão e pelo plano desenvolvimentista do presidente Juscelino Kubistchek, intitulado "50 anos em cinco", com investimentos em infraestrutura, rodovias, hidroelétricas, aeroportos, além do fomento à indústria nacional e a construção da nova capital, Brasília, inaugurada no início de 1960. O país atravessava por uma modernização no modo de consumo, e, semelhante aos Estados Unidos da América, este avanço era um contraponto em uma sociedade ainda marcadamente rural aonde se via a efervescência de movimentos de esquerdas, influenciados pela União Soviética e pela Guerra Fria.

O Movimento Nacional Independente (MNI) foi fundado em 8 de junho de 1958, presidida pelo Dr. João Rodrigues, (SILVA, 2006:166) na ocasião Delgado reúne-se com representantes locais e nacionais dez dias após as eleições no escritório do advogado Gustavo Soromenho. O movimento preconizava a continuação da luta pela democracia iniciada nas eleições, com os objetivos de buscar a legalidade pela reunião e realização de comícios, apoiar moralmente, legalmente e quando possível financeiramente, as vítimas da repressão, bem como a "liberdade de lutar pela instituição das liberdades democráticas". Para tal escreveu-se um documento formal com o pedido para que o movimento funcionasse legalmente, porém, como era de se esperar o pedido de autorização foi negado, e o MNI seguiu em uma semiclandestinidade pautada em planos e golpes de estado. Como exemplo as cartas escritas por Delgado aos chefes do EstadoMaior das Forças Armadas, apelando aos generais que reconhecem as eleições, protestassem pela troca de oficiais, entre demais itens, documento que acabou sendo negado (MOREIRA, 1990: 23).

A primeira sede do MNI no Brasil ficava no Rio de Janeiro, mesma cidade da Associação General Humberto Delgado, porém as ações do movimento em Portugal eram muito abstratas e estavam presentes mais nas palavras do general do que em ações concretas e segundo as memórias de Miguel Urbano Rodrigues, “após as eleições de 1958 não tinha existência e nem havia condições para se estruturar em Portugal, a continuidade 
do MNI foi muito mais figurativa, do que ativa em si" (RODRIGUES, 2002b: 63), mesmo assim Delgado assume como chefe da oposição no exílio, buscando continuidade nas lutas do MNI. Um conciliador destas diferentes facções existentes no exílio, trazendo para o Brasil o MNI que deveria se organizar em torno “do líder sufragado”. Lançou, em 1959, a diretiva Geral número 6, que estabelecia a fundação do MNI no Brasil, que daria continuidade à Candidatura Nacional Independente, com intuito de representar a unidade na oposição. Para tal definiu os órgãos competentes e nomeou, ele mesmo, as pessoas ligadas ao movimento como Henrique Galvão, Tomás Ribeiro Colaço, Francisco Oliveira Pio e Luís Carvalhal (SILVA, 2006: 181).

Esta Directiva não foi muito bem aceita pelos oposicionistas brasileiros, especialmente os envolvidos com o jornal Portugal Democrático, os quais Delgado considerava comunistas com vontade de poder, e que não reconheciam o MNI:

\footnotetext{
O Partido Comunista provou ser outro obstáculo, bem como o mais antigo jornal oposicionista no Brasil - Portugal Democrático - que se opunha a qualquer plano para derrubara ditadura por meios violentos. Preferiam fazê-lo por meio de eleições, mas não explicavam como tencionavam consegui-lo com as eleições que o governo português autorizava (DELGADO, PACHECO \& FARIA, 1998: 173).
}

Foi escrita uma carta com 39 signatários repudiando a ação de Delgado e explicando que estavam a longa data combatendo o regime, discordavam da estrutura do movimento, e diziam que o mesmo ia contra as leis brasileiras, e que o exílio brasileiro era considerado periferia dentro do movimento de oposição e não caberia à periferia dirigir a oposição e ação direta de derrubada do Estado Novo (SILVA, 2006: 183).

O desentendimento da oposição no exílio brasileiro aumentou com a publicação do artigo "E depois de Salazar?", de Miguel Urbano Rodrigues no Portugal Democrático, aonde propunha um debate acerca do futuro do país, e sua nova organização política e social para além do Estado Novo. No texto o autor sugeriu um socialismo aberto, com contornos por serem definidos pelo povo. Já Victor da Cunha Rego, em contrapartida, publicou uma resposta apontando os projetos e caminhos ideológicos que a tomada do poder deveria galgar em Portugal, mostrou a importância do pensamento individual, mas acentuou na execução prática de tais projetos (RODRIGUES, 2002b: 178). Rego, assim como a sugestão de Rodrigues, chamou a atenção para a necessidade de se pensar no 
Portugal do futuro, de como a população deveria organizar-se para que o país não caia em um caos e mergulhasse novamente em outra ditadura, ou para evitar que as regras fossem ditadas por sobreviventes ao regime ou capitalistas protegidos pelo mesmo. Para tal a sociedade deveria estar unida dentro de um sentimento, aonde a revolução deveria ser alimentada por quem sonhava e percebia os problemas da nação, arquitetada em parceria com técnicos aptos para fazer as mudanças necessárias. O artigo clamava a todos pela unidade e por levar em conta todos os partidos, aproveitando a organização e a doutrinação comunista, que seriam necessárias para a reorganização do Estado português. $\mathrm{O}$ autor encerrou considerando o anticomunismo como um mal estúpido, pois, aos que pensavam que o PCP poderia mergulhar o país em outra ditadura, esqueceram do contrapeso que faria desta uma concepção impossível: a igreja católica, igualmente doutrinária, mas com séculos de experiência e muito bem fundamenta na sociedade.

Vitor Ramos e Manuel de Moura, dois militantes do PCP do jornal Portugal Democrático, não haviam levantado objeções. Para Ramos, o debate sobre o que viria depois da queda do regime era muito menos útil do que discutir a queda em si (SILVA, 2006: 179). Estas questões sobre a forma de ação e o que fazer pós Salazar somente fez ruir uma estrutura que já estava rachada, principalmente no que tangia às diferenças políticas. Insatisfeito com o rumo que o Portugal Democrático estava tomando, Urbano Rodrigues então procurou Víctor da Cunha Rego para esboçar sua ideia sobre o lançamento de um novo jornal, que também fora apresentado e aprovado por Henrique Galvão. Humberto Delgado alinhou facilmente com o jornal, pois não gostava de Sarmento Pimentel e Paulo de Castro, e tinha um pé atrás com os comunistas, mesmo mantendo boas relações com alguns colegas. O projeto recebeu ainda o apoio de Tomaz Ribeiro Colaço e Francisco Vidal do Rio de Janeiro e de Pedroso Lima e Santana Mota, de São Paulo, não obstante, são os mesmo integrantes que haviam apoiado Miguel Urbano Rodrigues na criação do natimorto Movimento Manifesto (RODRIGUES, 2002b: 189). Segundo Rodrigues o novo jornal:

Teria uma linha revolucionária [...] não suportávamos a linguagem dos republicanos históricos, não acreditávamos na democracia burguesa, nem na tese sobre a desagregação irreversível do fascismo. Defenderíamos uma unidade voltada para a acção e não uma unidade imobilista (RODRIGUES, 2002b: 180). 
Junta-se a isto as ações e palavras proferidas por Humberto Delgado logo após sua chegada, que acabou por dividir a oposição no Brasil e fez com que os portugueses tomassem partido. Esta era justamente a intenção de Delgado, exaltar os ânimos e ver as reações de quem estava, ou não, com ele. Delgado logo percebeu que a concentração maior de oposicionistas estava na cidade de São Paulo e, portanto, lá também ficaria estabelecida a sede central do MNI. Assim, o jornal Portugal Livre foi declarado como órgão oficial do movimento, fato que estava explícito nas primeiras edições do jornal, principalmente na primeira: "Portugal Livre não é apenas um jornal de oposição - é o órgão da Democracia Portuguesa, o porta-voz do MNI, cada um dos seus leitores que o faça chegar a Portugal e prestará à causa da Liberdade um grande serviço". Era perceptível reconhecer "a voz" de Delgado nas mensagens das primeiras edições e, de fato, o jornal tinha um caráter exclusivista e centralizador.

Assim, o jornal nasceu da ânsia por uma nova solução ao modo de ação da oposição a partir do exílio, impulsionado pela campanha de 1958 e pela vinda de Delgado para o Brasil. Contudo o general não era o protagonista ou figura central desta reorganização política da oposição no exílio brasileiro, mas sim funcionou como catalisador de forças e vontades que já se apresentavam latentes no seio da oposição. Ainda que o nome do jornal, Portugal Livre, remeta à campanha de Delgado e aos inúmeros cartazes colados nas ruas de São Paulo para recepcionar o general em terras brasileiras.

Para editar e colocar em circulação o Portugal Livre, não houve tantas dificuldades como aconteceu com o início do Portugal Democrático, isto por trata-se de um jornal redigido, acima de tudo, por jornalistas, que soma a própria experiência dos envolvidos. Os redatores principais eram Miguel Urbano Rodrigues, Victor da Cunha Rego e Santana Mota - os três advindos do Diário Ilustrado e colegas de trabalho no $O$ Estado de S. Paulo - contavam ainda com o apoio de jornalistas e escritores brasileiros, como Paulo Duarte e Cláudio Abramo e claro, figuras controversas supracitadas, como Henrique Galvão e Humberto Delgado.

O capitão ex-deputado por Angola, Henrique Galvão nunca esteve exilado no Brasil antes do assalto ao Santa Maria, nem tampouco participou das reuniões da redação e da administração do jornal, mesmo assim foi o colaborador que mais publicou no jornal, em um total de quinze artigos assinados, sem contar as quatro últimas edições, repletas de artigos assinados pelo Diretótio Revolucionário Ibérico de Libertação (DRIL), do qual Galvão era líder juntamente com Sotomayor. Os textos de Galvão eram enviados ora de 
Portugal, ora de Buenos Aires, e a maioria de Caracas, Venezuela, país que lhe concedeu asilo político sem antes pedir asilo no Brasil. Em carta enviada para o então presidente do Brasil, JK, Galvão afirma que fora convidado pela Universidade de Caracas para lecionar em um curso de estudos africanos, e ainda demonstra sua indignação e tristeza em virtude da demora para obter o visto para o Brasil a partir da embaixada brasileira situada em Buenos Aires (GALVÃO, 1959: 3).

Se o jornal pretendia agir, mais do que noticiar, Galvão é o exemplo maior desta ação: contatara uma série de portugueses e espanhóis em Caracas para preparar a “Operação Dulcinéia", mais conhecida como o assalto ao transatlântico Santa Maria. Além disto, ele era dono de uma opinião forte, sem meias palavras e beirava a inconsequência, seja para falar de comunistas ou expor seu ponto de vista acerca das colônias portuguesas, ou ainda através da literatura, com a coluna "Pax Lusitana", Galvão publicou uma série de poesias engajadas, algumas destas inéditas.

De modo generalizante os textos do jornal seguiam uma estrutura básica, que passava pela desconstrução do Estado Novo, com caracterização extremamente pejorativa e caricata de Salazar, até chegar numa exaltação do Brasil e sua relação com Portugal para terminar com glorificação à liberdade e à democracia. Entretanto, os textos de Miguel Urbano Rodrigues mostraram-se mais maduros e propunham, em sua maioria um debate mais rico e caloroso com questões pontuais e detalhadas, tendo escrito um total de oito artigos assinados sobre seu nome, além do cargo de redator.

\section{Estrutura e organização do novo jornal}

O jornal passava por uma verdadeira maratona para chegar às ruas mensalmente, cujos integrantes e colaboradores faziam uma ou duas reuniões mensais para tratar dos temas, selecionar textos, dividir funções e solucionar problemas referentes à parte burocrática. A sede provisória ficou no centro da cidade de São Paulo. No quinto andar da Rua Direita, em um edifício muito bem localizado, contudo ficaram somente um mês neste endereço. Já em janeiro de 1960 a redação muda para a rua Quinze de novembro, e passa a ter um expediente fixo. A sala não era muito grande, e durante os dois primeiros meses ficava quase sempre vazia, com algum secretário ou voluntário, mas de qualquer forma o local funcionava mais como ponto para receber correspondências do que como uma redação propriamente dita. Os envolvidos faziam jornadas duplas para mantê-lo, 
assim a boa vontade e o voluntariado eram indispensáveis para seu pleno funcionamento. Victor da Cunha Rego e Miguel Urbano Rodrigues desdobravam-se em muitas tarefas burocráticas, para além das tarefas de redação, como escrita e diagramação, acompanhavam a montagem tipográfica e iam aos correios, pois era através de cartas que a relação com diversos colaboradores era mantida, sobretudo a distribuição internacional.

A presença de um número maior de jornalistas profissionais na redação do Portugal Livre, fez com que este apresentasse um projeto gráfico ligeiramente melhor que o Portugal Democrático (RODRIGUES, 2002b: 191). O jornal apresentava um formato padrão para época: continha, em média, oito páginas, sendo cada uma delas dividida em cinco colunas contendo os textos, que por sua vez eram ligeiramente mais extensos que os encontrados em jornais diários, isto por se tratar de um jornal mensal, cujos escritores possuíam um tempo maior para preparar artigos mais longos. Aqui e acolá apareciam algumas imagens de personalidades da oposição, de elementos do regime ou das colônias africanas, em uma média de quatro fotografias por edição. O Portugal Livre não fazia cobertura fotográfica completa, tal como seu "rival", que disponibilizava mais de uma folha para ilustrar um evento, como exemplo a cobertura da chegada de Humberto Delgado, ou jantares comemorativos. As fotografias eram cedidas por colaboradores com acervos pessoais ou através de jornalistas colegas de outros jornais, como o OESP.

O capital inicial para editar e colocar o jornal em circulação era escasso e, portanto, cada ajuda era bem-vinda. Além da contribuição dos envolvidos através dos serviços prestados, cada integrante se comprometia a ajudar com uma quantia mensal, que não era fixa. Outra forma de contribuição vinha de seu financiador, Joaquim Ribeiro Bastos, pai de Celso Ribeiro Bastos que mais tarde viria a contribuir também com o DRIL. Em um segundo momento três novas fontes de renda ajudaram a manter o Portugal Livre, tais como os escassos anúncios publicitários, as assinaturas, cheques e contribuições do estrangeiro.

Uma pequena parte dos fundos para a manutenção e edição do jornal era proveniente de anúncios feitos em suas páginas, uma vez que estes eram raros, tendo havido somente duas propagandas brasileiras em todas as edições. Ambas as propagandas eram bem ilustradas e informativas. A primeira era uma chamada publicitária de folha inteira da NAB - Navegação Aérea Brasileira S.A, que apresentava tarifas baixas com voos a partir de São Paulo para todo o Brasil. O outro era da empresa Ypiranga AutoLocadora, com filiais em São Paulo e Rio de Janeiro. O fato é que o Portugal Livre saia 
em tiragem limitada e para um público bem especifico, e isto poderia dificultar a venda de suas páginas para anúncios comerciais.

Nos primeiros seis meses o jornal tinha uma circulação menor, com tiragem de três mil exemplares, e quase sempre conseguia vender um pouco mais que a metade deste valor. O preço de um exemplar avulso era de $\mathrm{Cr} \$ 5,00$ (cruzeiros), enquanto que a assinatura regular anual era de $\mathrm{Cr} \$ 100,00$. O preço de capa não era caro, se comparado aos demais periódicos brasileiros da época, incluindo jornais diários, que custavam uma média de Cr\$3,00 por edição. Já nos dois últimos meses passou a custar Cr\$10,00 em São Paulo e Cr\$15,00 para os demais estados.

Havia representantes do jornal situados em outras cidades brasileiras, a exemplo de Luis de Almeida Carvalhal, no Rio de Janeiro e Virgolino Pereira Vilhena em Belo Horizonte, capital de Minas Gerais. Suas funções eram tratar de assuntos administrativos, pagamentos e assinaturas, como também a venda avulsa de alguma edição. A partir de abril de 1960 o jornal passou a ser vendido em Paris, França, em um quiosque de jornais na região central da cidade.

Um dos principais objetivos do jornal era divulgá-lo para a colônia portuguesa no Brasil e, acima de tudo, dentro do território português, o que configurava como a tarefa mais complicada.

A Portugal chegavam algumas dezenas de exemplares. A maioria seguia em envelopes timbrados de instituições inexistentes (Como nomes sagrados como os de Vasco da Gama, Pedro Álvares Cabral, Nossa Senhora de Fátima, e de congregações religiosas fantasistas (RODRIGUES, 2002b: 189).

Em todas as dezesseis edições do Portugal Livre encontram-se apelos para enviarem o jornal para Portugal, pois, mais do que escrever para oposicionistas exilados o jornal deveria ser lido por conterrâneos que não tinham acesso a muitas informações, em virtude da censura, como no trecho seguinte: "para o objetivo que presidiu o lançamento de "Portugal Livre" seja alcançado, é indispensável que o órgão do MNI chegue a todas as vilas de Portugal, levando lhes, mês após mês as palavras de esperança de Humberto Delgado" (Portugal Livre, 1959, ed. 1, Fl. 5).

Um correspondente de Lisboa reportou sobre a ampla repercussão das primeiras edições do Portugal Livre em Lisboa, inclusive entre os militares, aonde eram possíveis 
ver copias mimeografadas dos artigos nos gabinetes. Esta é uma informação que não foi possível verificar a veracidade, mas a PIDE, a polícia política, sabia da existência do jornal, e mantinha a alta cúpula do Estado Novo informada sobre suas ações e matérias. Durante a pesquisa foram encontrados recortes de jornal nos arquivos Oliveira Salazar, e relatando o início de suas atividades em terras brasileiras.

O jornal recebia textos de colaboradores, não somente para dar conta da demanda de artigos sobre Portugal de Salazar, mas para expor pontos de vista de determinados especialistas que escreviam dossiês temáticos espalhados em várias edições do jornal. Por outro lado, a colaboração em forma de artigos era uma maneira de contribuir para oposição no exílio, sobretudo para aqueles que não residiam em terras brasileiras. Assim, exerce outra função importante: de conectar diferentes pessoas ou núcleos oposicionistas situados em diferentes partes do mundo, tais como França, Venezuela, Argentina, Argélia, Angola, Estados Unidos e o próprio Portugal. As colaborações vinham sob nomes reais, quando estes residiam fora de Portugal, anônimo ou sob pseudônimo, principalmente de correspondentes especiais de Lisboa ou Porto, que precisavam manter sua identidade longe do crivo da PIDE. Infelizmente não foi possível descobrir todos estes nomes secretos envolvidos com o Portugal Livre, lacuna criada em virtude de uma clandestinidade necessária pela qual passavam estes colaboradores.

\section{As críticas à relação de Juscelino e Salazar}

Como se tratava de um jornal editado em território brasileiro, era inevitável ou mesmo compreensível, que assuntos pertinentes aos dois países figurassem nas páginas do Portugal Livre. Vimos como os exilados misturavam-se em diversos círculos, como em redações de jornais ou no meio acadêmico, em uma relação que por vezes transpassava os interesses políticos. Além disto, o discurso dos colaboradores era repleto de agradecimentos e imagens construídas com base na História em comum das duas nações com uma pré-estabelecida relação de irmandade entre ambas.

O governo brasileiro em nenhum momento proibiu a circulação do Portugal Livre, contudo isto não significou que a sua relação com os oposicionistas era tranquila. Ao contrário disto, o presidente Juscelino Kubitschek protagonizou alguns dos temas mais corriqueiros percebidos nas folhas do periódico e acabou por ser alvo de críticas de jornalistas, políticos, brasileiros e portugueses. Como exemplo, sua viagem para Portugal 
a convite de Salazar em virtude das comemorações henriquinas e querelas envolvendo o embaixador Álvaro Lins no "Caso Delgado". 6

É interessante aqui destacar dois artigos, entre todos os colaboradores que escreveram sobre o tema, nas páginas do Portugal Livre. O texto "Brasil - caução do colonialismo português" de Eduardo Lourenço, publicado na edição nove, o qual analisa a visita do presidente sob outro ponto de vista, ao contrário dos demais autores que buscavam o elemento político para justificar a visita, Lourenço procurou "atingir a natureza da viagem presidencial" através de uma análise cultural (LOURENÇO, 1976: 37-49).

Assim, povo ex-colonizado de Portugal, o povo brasileiro surgia agora na cena internacional celebrando as glórias expansionistas do Infante D. Henrique a par com o povo colonizador, permitindo que, por via da união celebratória entre ambos, Portugal se apresentasse ao mundo como país colonizador exemplar (REAL, 2003: 58).

Outro autor a mencionar a simbologia por trás do encontro dos líderes dos dois países foi Costa de Amorim, na crônica subintitulada “À propósito de uma viagem”. A pena ácida, bem-humorada e crítica de Amorim chama o líder brasileiro de "Doutor Juscelino", referência a formação de médico do presidente brasileiro, a quem faz às vezes de "quase eleitor do Sr. Salazar" visto que sua presença nas celebrações daria foro de legalidade "a um governo de fantoches" (AMORIM, 1960).

Para um último recurso contra a viagem, a redação enviou uma carta em apelo ao senador pelo estado do Rio de Janeiro Afonso Arinos de Melo Franco para interceder junto ao senado na não realização da visita de JK. O senador fez um pronunciamento neste sentido, mas não recebeu o apoio aberto de todos os colegas, sobretudo aqueles simpáticos com Salazar e Kubitschek, ao afirmarem que não caberia aos portugueses reclamarem sobre isto, ao passo que o jornal respondeu que não aceitava a tese de que os problemas brasileiros não poderiam ser opinados por estrangeiros. O jornal dedicou o editorial da décima primeira edição à visita de fato, na qual trazia duas fotografias na

\footnotetext{
${ }^{6}$ Álvaro Lins, foi jurista, jornalista, escritor, acadêmico. Posteriormente foi chefe da Casa Civil de JK e depois diplomata na embaixada brasileira em Lisboa. Após as ameaças de morte por parte do Estado Novo português a Humberto Delgado em 1958, este hospedou-se na embaixada brasileira. JK demorou para conceder asilo político ao general. Irritado, Lins voltou ao Brasil, demitiu-se e cortou relações com o presidente. Os exilados brasileiros o elegeram como um dos símbolos de ligação entre Portugal e Brasil na luta contra o Estado Novo português.
} 
capa: Salazar e JK sorrindo lado a lado, e outra de Álvaro Lins abaixo. A redação reconheceu que a visita do presidente brasileiro representava uma vitória para o regime ao afirmar que depois de uma análise realista, uma declaração eufórica não seria prudente. A crise diplomática gerada com o asilo de Humberto Delgado dois anos antes foi sanada com a presença do presidente brasileiro nas comemorações henriquinas e finalizado com acordos e assinatura falsos e de fachada, como tratado de extradição e o de dupla nacionalidade, que regulariza a situação de emigrados.

Se pensarmos os assuntos tratados pelo jornal, ao longo de sua curta existência, em forma de blocos, é possível considerar que o colonialismo, e demais temas ligados a ele, foi o mais abordado, e também um dos mais polêmicos. O mundo estava, aos poucos, condenando as velhas nações colonialistas e o jornal percebeu, assim como já vinha fazendo o Portugal Democrático, que denunciar os abusos e problemas ocorridos em África, ajudaria a dar sobrevida às lutas oposicionistas através de apoio de nações estrangeiras. Este fator continuou mesmo depois do fechamento do Portugal Livre, isto porque durante a ditadura militar brasileira o Portugal Democrático foi o único jornal que falou abertamente de luta de classes sem ser fechado pela censura, visto que os militares não queriam ir contra um jornal assumidamente anticolonialista, a frente de toda comunidade internacional, e em plena guerra colonial ocorrendo na África. Mas, mesmo sendo o assunto mais discutido, não significa que as opiniões estivessem em uníssono, pelo contrário, foi um dos fatores que ajudou transformar em abismo, os rachas já existentes entre a oposição.

Conforme exposto anteriormente, a própria fundação do jornal previa uma mudança de atitude frente à oposição no exílio, porém a atitude, ou ação, quase nunca era de comum acordo entre os exilados, e este desacordo não se restringiu somente entre as diferenças entre democratas e comunistas, ou as ideias do Portugal Democrático contra o Portugal Livre. A falta de coesão estava presente na redação, a opinião mudava a cada matéria, a cada página, influenciados pelo desejo de ação vindo do DRIL, em Caracas, ou por Humberto Delgado, que, aos poucos perdia sua credibilidade. As perguntas mais latentes eram: como derrubar o Estado Novo? Devemos fazê-lo sozinhos ou com ajuda popular? Uma revolução, golpe militar ou revolta interna? Temos que esperar o regime abrir-se aos poucos? Qual forma de governo adotar depois, e importa pensar nisto agora? Eis agora a opinião da redação, colaboradores, leitores e críticos sobre algumas destas questões. 
Não havia menções diretas ou ataques em todo o período de coexistência dos jornais Portugal Democrático e Portugal Livre; os jornais ignoravam-se mutuamente, fato que Miguel Urbano Rodrigues já havia constatado em suas memórias (RODRIGUES, 2002b: 154). Entretanto, era possível perceber uma série de notas indiretas, ou mesmo nos textos anticomunistas de Galvão e Delgado, e os comunistas, por sua vez, estavam ligados diretamente ao $P D$. Um dos poucos artigos que toca na questão da unidade no Portugal Democrático, mas sem mencionar nomes e partidos, é de autoria de Manuel Dores, escrito em novembro de 1960, intitulado “A Oposição, as Colónias Portuguesas e a unidade", onde o autor faz uma distinção oportuna, ao afirmar que "unidade não quer dizer união pura e simples, abdicação de princípios, filosofia ou teorias seguidos pelos diversos setores ou partidos" (DÔRES, 1960: 3). Para isto Dores propõe que sejam discutidas e respeitadas, estas diferenças, para assim cada um distinguir o limite do outro e encaixá-lo dentro de um projeto maior, e que não devem parar de militar ou participar de outros projetos políticos, pois isto é indispensável saudável para uma nação que se quer livre e democrática.

A participação popular no processo revolucionário, ou mesmo o despertar de uma consciência, são pontos fulcrais nas discussões do jornal. Segundo Rego, o importante era criar as "bases de uma politização popular em larga escala que possibilite ao povo português a escolha livre e consciente num futuro próximo", pois de formação política não exclui o sentimento revolucionário e de mudança (REGO, 1960: 1). Já Mota afirmou que o povo português não possuía a vaga ideia de como sair do regime, cabendo à oposição trilhar este caminho e ditar as bases deste processo. Assim, mesmo o povo aqui colocado como "massa inconsciente", não deveria perdê-lo de vista. Santana Mota afirmou que não bastava que um general se insubordinasse, era preciso superar a fase de supervalorização do alto escalão do exército no processo revolucionário, e nascer do povo o desejo de liberdade, mas muito mais do que liberdade proveniente da democracia, há a necessidade de rever a propriedade privada, saúde e educação, além de sanar problemas na tributação, previdência e assistência social, passando desde o latifúndio no Alentejo até a aparelhagem da indústria, para poder alcançar uma autossuficiência econômica com a liberdade e autonomia sendo, paulatinamente, concedida ao ultramar. O autor concluiu dizendo que a ditadura de Salazar só foi instituída, em parte, pela projeção e esperança que o próprio povo depositou no estado, o mesmo vale para o projeto de um Portugal para além do Estado Novo, se o povo não se prontificar a participar, tanto na derrubada quanto 
nas discussões do novo governo e delegar as funções aos grupos políticos, não sairá da miséria (MOTA, 1960:3).

O fechamento do jornal ocorreu em meio ao atribulado, e midiático, assalto ao paquete Santa Maria, quando 23 homens armados tomaram o transatlântico português nas Bahamas, em meio a morte de um marinheiro, o governo dos EUA interveio e pós fím à ação política. A influência da forma de ação proposta pelo evento estava implícita em todas as páginas, como a disposição das matérias na última folha, que é bastante emblemática neste sentido. Havia um comunicado do DRIL à imprensa, na parte superior e ocupando quase toda a folha, enquanto que logo abaixo vinha o comunicado oficial de despedida do jornal. A nota do DRIL foi direcionada aos jornais de todo o mundo, com o objetivo de divulgar, através de doze pontos, as intenções da Operação Dulcinéia. Afirmavam ser contrários a qualquer transição que não seja a vontade do povo e convidavam os interessados a ingressar em seus quadros. Ao final, agradece a hospitalidade do governo e do povo brasileiros e diz não ter intenções de violar sua legislação, ou seja, não estavam dispostos a criar grupos armados dentro do país que os acolheu. Já a nota na íntegra, dizia:

Portugal Livre despede-se temporariamente dos seus leitores, por lhe ser materialmente impossível sair com a regularidade que mantivera até janeiro: a maioria dos seus redatores foi convocada a funções de mais ação. O seu objetivo é o mesmo; apenas chegou a hora de os atos substituírem as palavras e de se tentar por em prática o que se vinha preconizando em teoria. Que o reaparecimento deste jornal se dê numa atmosfera de mais liberdade e mais justiça em terras portuguesas, são os votos com que nos despedimos, por ora, de todos os nossos leitores (Portugal Livre 1969: 8).

Mas o que levou ao fechamento do jornal? Vários fatores ajudariam para o fechamento da publicação, assim não se pode elencar um único motivo, mas podem-se destacar cinco principais razões, que, combinados, levaram ao seu fim. Entre eles estão a nova postura da oposição frente à tese da ação direta; comprometimento dos redatores com outros projetos; aumento das divergências políticas e pessoais entre os colaboradores, e a releitura da questão da unidade.

A menos de cinco meses do fechamento da redação, Miguel Urbano Rodrigues havia realizado um inflamado discurso, em um jantar comemorativo do 5 de outubro, 
sobre a necessidade de cooperação e comprometimento de todos os portugueses juntamente com as publicações oposicionistas, ao fazer a comparação de quantas páginas poderiam ser impressas com o valor do ingresso para o banquete comemorativo, mas podemos perceber claramente a mudança no discurso, apresentado pelo mesmo autor, em um artigo da última edição que afirmava: "Acreditamos sinceramente que, dada a possibilidade de uma ação direta capaz de derrubar Salazar e Franco, a edição deste jornal acarretaria em encargos financeiros e físicos melhor empregues nas operações que, segundo tudo indica, serão desencadeadas em breve" (Portugal Livre, 1961:2).

Agora os fundos financeiros não eram mais necessários para produção de papel, e sim, para fomentar as ações, em outras palavras, não havia mais a vontade de escrever sobre a revolução, e sim fazê-la. E isto está conectado diretamente ao comprometimento dos redatores principais, Miguel Urbano Rodrigues e Victor da Cunha Rego, que se viam envolvidos, e empolgados, diretamente com o assalto ao Santa Maria e, portanto, não havia mais tempo para cuidar de outras tarefas, além da dupla jornada como jornalistas e oposicionistas. Tanto que, logo após a estes eventos, Rodrigues propôs para o editor do jornal OESP, Júlio de Mesquita Filho, uma viagem para África portuguesa, aonde realizaria uma série de reportagens sobre a Guerra Colonial (RODRIGUES, 2002b: 222). Havia quem escrevesse colunas e artigos, mas quem estaria disposto a reunir todos os textos, diagramar, distribuir e cuidar das assinaturas?3

A falta de disposição e comprometimento aumentava, na medida em que crescia também, as diferenças ideológicas e desentendimentos pessoais. As declarações e propostas neocolonialistas de Henrique Galvão e Humberto Delgado geraram uma grande decepção e descontentamento entre os oposicionistas, sobretudo por estes tentarem continuamente, se estabelecerem com porta-vozes da oposição. A postura excludente, e o forte personalismo de Delgado poderiam aglutinar alguns fiéis seguidores, mas afastavam muitos outros. Ambos não faziam questão de esconder suas opiniões sobre o comunismo, e isto corroborou em muito para a separação do grupo.

\section{Conclusão}

Terminado este artigo é interessante fazer algumas considerações, primeiro, vou resgatar a pergunta da introdução que um jornal, editado no exílio e de vida tão curta, pode revelar-nos acerca da oposição ao Estado Novo? Percebemos que a reunião de 
exilados em terras brasileiras se deu em torno de dois elementos: o trabalho, principalmente como jornalista, e a oposição ao Estado Novo. Entretanto isto não significa que os laços lusitanos seriam suficientes para unir a comunidade em torno de uma luta. Haviam disputas políticas, espaços de poder, sentimento anticomunista, pautas distintas na forma de derrubar Salazar e o que fazer depois dele, além de forte personalismo como as figuras de Delgado e Galvão. Estava em questão a próprio alcance do exilado enquanto agente político no além mar. O Portugal Livre seria então uma síntese no meio de forças, que por mais que pareçam antagônicas, reuniu forças para discutir um projeto prático para derrubar o Estado Novo. Ademais, este trabalho inserese em uma discussão que mais ampla sobre a colaboração de intelectuais portugueses e brasileiros, sobre redes de solidariedade e poder e oposição.

\section{Fontes}

AMORIM, Costa de (1960). Crônica do Rio: carneiro com batatas. Portugal Livre, ed. 6, abril, Fl. 4. (Centro de Documentação 25 de Abril - CD25a, Coimbra).

CARTA para Presidência do Conselho de Ministros (1960). Arquivo Salazar, PC-77 cx. 593, subd. 30. Arquivo Nacional Torre do Tombo, Lisboa, Portugal.

DÔRES, Manuel (1960). A Oposição, as Colónias Portuguesas e a unidade. Portugal Democrático. Ed. 4, Fl. 7. (CD25a).

GALVÃO, Henrique (1959). Galvão e o Brasil. Portugal Livre, Portugal, Ed.1, Fl.1 nov. JORNAL Portugal Democrático (1959), Ed.17, Fl. 1. (CD25a).

JORNAL Portugal Livre (1959), ed. 1, Fl. 5, nov, (CD25a).

JORNAL Portugal Livre. Carta ao Sen. Afonso Arinos (1960).Ed.10, Fl. 2, ago. (CD25a). JORNAL Portugal Livre. A posição atual (1960). Ed.11, Fl. 2. Set. (CD25a).

JORNAL Portugal Livre Os acordos de Lisboa: uma mistificação (1960). Ed.11, Fl. 3 , set. (CD25a).

JORNAL Portugal Livre Ed.42, Fl. 7. (CD25a).

JORNAL Portugal Livre. Oposições. (1961) Ed.16, Fl. 2, fev/mar (CD25a).

JORNAL Portugal Livre. Comunicado do DRIL a imprensa (1961). Ed.16, Fl. 8. Fev/mar (CD25a).

JORNAL Portugal Livre (1961). Ed.16, Fl. 8, fev/mar (CD25a).

JORNAL Portugal Livre (1959), Ed. 1, Fl. 5, Nov. (CD25a).

JORNAL Portugal Livre, 1960 - ano da esperança. (1960). Ed.3. Fl. 6. Jan.(CD25a).

MOTA, Santana (1960). Compete ao povo. Portugal Livre, Ed.6, abr.

REGO, Victor da Cunha (1959). Portugal Livre, ed.1, nov.

\section{Referências Bibliográficas}

ALMEIRA, Carlos, BARRETO, Antonio (1970). Capitalismo e emigração em Portugal. Coleção Cadernos de Hoje, Lisboa. 
BATISTA, Elisabeth (2007). Entre a literatura e a imprensa: percursos de Maria Archer no Brasil. Tese (Doutorado em Letras). Universidade de São Paulo, São Paulo.

DELGADO, Iva; PACHECO, Carlos; FARIA, Telo (Orgs.) (1998). Humberto Delgado - as eleições de 58. Lisboa: Editora Veja.

FIUZA, Alexandre Felipe (2006). Entre um samba e um fado: a censura e a repressão aos músicos no Brasil e em Portugal nas décadas de 1960 e 1970. Tese (Doutorado em História). Universidade Estadual Paulista "Júlio de Mesquita Filho", Assis, SP.

FREITAS, Eduardo de (1990). O fenômeno emigratório: a diáspora européia. In: Portugal Contemporâneo. Vol. V. Lisboa, Publicações Alfa.

GOBBI, Márcia Valéria Zamboni; FERNANDES, Maria Lúcia Outeiro \& JUNQUEIRA, Renata Soares (Orgs.) (2002). Intelectuais portugueses e a cultura brasileira. Depoimentos e Estudos. São Paulo: EDUNESP/EDUSC.

HOBSBAWM. Eric (1995). Era dos extremos: o breve século XX (1914 -1991). Trad. Marcos Santarrita. São Paulo: Companhia das Letras.

LEMOS, Fernando \& LEITE, Rui Moreira (Orgs.) (2002). A Missão Portuguesa. Rotas entrecruzadas. São Paulo: EDUNESP/EDUSC.

LOURENÇO, Eduardo (1976). Brasil - caução do Colonialismo Português (1960). In: . O fascismo nunca existiu. Lisboa: Publicações D. Quixote, pp. 37-49

LOFF, Manuel (1994). As duas ditaduras Ibéricas na Nova Ordem Eurofascista (19361945). Tese (Doutorado em História Contemporânea). Instituto Universitário Europeu, Firenze.

MADEIRA, João (2010). O PCP entre o rescaldo da campanha de Delgado e os caminhos para derrubar o regime (1958-1959). In: PAULO, Heloísa (Coord.). Memória das Oposições (1927-1969). Lisboa: Minerva Coimbra.

MATTOS, Heloísa H. G. (1989). Modos de olhar o discurso autoritário no Brasil (19691974), o noticiário de primeira página na imprensa e a propaganda governamental na televisão. Tese (Doutorado em Comunicação). Universidade de São Paulo, São Paulo.

MENESES, Filipe Ribeiro de (2010). Salazar. Lisboa: Publicações D. Quixote.

MOREIRA, António (1990). A crise: do "terramoto Delgado" ao golpe da Beja. In: REIS, Antonio (Dir.). Portugal contemporâneo. Vol. V. Lisboa: Publicações Alfa, pp. 2136.

NEVES, José (2010). Comunismo e nacionalismo em Portugal: política, cultura e história no século XX. Lisboa: Editora Tinta da China.

NÓVOA, António (1990). Salazarismo e cultura. In: OLIVEIRA, César de; ROSAS, Fernando; Et Al. Portugal e o Estado Novo. (1930-1960). Vol. XVII. Lisboa: Presença.

OLIVEIRA, César (1992). A Evolução Política. In: SERRÃO, Joel \& MARQUES, A. H. de Oliveira (Dir.). Nova História de Portugal. vol. XII, Portugal e o Estado Novo (1930-1960). ROSAS, Fernando (coord). Lisboa: Presença.

PALLA, Maria Antonia (1989). A Revolução da Imprensa, Apesar da Censura. In: REIS, Antônio (Coord.). Portugal Contemporâneo. Lisboa: Publicações Alfa.

PIMENTEL, João Sarmento 91974). Memórias do Capitão. Lisboa: Seara Nova.

PINTO, António Costa (1994). Os Camisas Azuis. Ideologias, elites e movimentos fascistas em Portugal. 1914-1945. Editorial Estampa: Lisboa.

PAULO, Heloisa (2000). Aqui também é Portugal: A colônia Portuguesa no Brasil e o Salazarismo. Tese (Doutorado em História). Universidade de Coimbra, Coimbra. (2010a). Um olhar sobre a oposição e o exílio no Portugal de Salazar. In: Memória das Oposições (1927-1969). Lisboa: Minerva Coimbra, pp. 183-193. 
(2010b). Da revolução ao exílio: trajetórias de vida e de combate. In: Memória das Oposições (1927-1969). Lisboa: Minerva Coimbra.

PINTO, António Costa. O Estado Novo português e a vaga autoritária dos anos 1930 do século XX. In: O Corporativismo em Português. Estado, Política e sociedade no salazarismo e no varguismo. Rio de Janeiro: Civilização Brasileira, 2007.

QUEIROZ, Guido Fabiano Pinheiro. Os Espelhos de Barradas de Carvalho: crônica política e historiografia de um exilado. Tese. Pontifícia universidade Católica, Rio de Janeiro, 2009.

REAL, Miguel. Democracia e anti-colonialismo em Eduardo Lourenço: 1959-1963. Metacritica Dossier. BD/ME, 2003.p. 58.

REIS, António. (Dir.) Portugal Contemporâneo. Vol V. Lisboa, Publicações Alfa. 1990.

ROSAS, Fernando (1989). A Crise do Liberalismo e as origens do "Autoritarismo Moderno e do Estado Novo em Portugal". Penélope, n. 2, pp. 97-114. (1990). O País, o regime e a oposição nas vésperas de 1958. In: REIS, Antonio (Dir.) Portugal Contemporâneo. Vol. V. Lisboa: Publicações Alfa, pp. 97-114 (1994). O Estado Novo, 1926-1974. In: MATOSSO, José (Dir.). História de Portugal, vol. VII. Editorial Estampa, Lisboa.

ROSA, Frederico Delgado (2008). Humberto Delgado - biografia do general sem medo. Lisboa: Esfera dos Livros.

RODRIGUES, Miguel Urbano (2002a). O Tempo e o espaço em que vivi - I - Procurando um Caminho (memórias) Porto: Campo das Letras. (2002b). O tempo e o espaço em que vivi - II - Revolução e Contra-revolução na América Latina (memórias) Porto: Campo das Letras.

RAMOS, Ubirajara Bernini. Portugal Democrático: um jornal de resistência ao Salazarismo publicado no Brasil. (Dissertação de Mestrado em História). Pontifícia Universidade Católica (PUC): São Paulo, 2004.

SILVA, Douglas Mansur da (2006). A oposição ao Estado Novo no exílio brasileiro, 1956-1975. Lisboa: Imprensa de Ciências Sociais.

SERTÓRIO, Manuel (1990). Humberto Delgado, setenta cartas inéditas. Lisboa: Publicações Alfa.

Artigo recebido em 30 de agosto de 2016.

Aprovado em 31 de maio de 2017.

DOI: $10.12957 /$ intellectus.2017.31654 